\title{
DNA-based nano-sized systems for pharmaceutical and biomedical applications.
}

\section{$\operatorname{AUTHOR}(\mathrm{S})$ :}

Nishikawa, Makiya; Rattanakiat, Sakulrat; Takakura, Yoshinobu

\section{CITATION:}

Nishikawa, Makiya ... [et al]. DNA-based nano-sized systems for pharmaceutical and biomedical applications.. Advanced drug delivery reviews 2010, 62(6): 626-632

\section{ISSUE DATE:}

2010-04-30

URL:

http://hdl.handle.net/2433/131742

\section{RIGHT:}

(c) 2010 Elsevier B.V.; この論文は出版社版でありません。引用の際には 出版社版をご確認ご利用ください。; This is not the published version. Please cite only the published version. 


\section{DNA-based nano-sized systems for pharmaceutical and biomedical applications}

Makiya Nishikawa, Sakulrat Rattanakiat, and Yoshinobu Takakura

Department of Biopharmaceutics and Drug Metabolism, Graduate School of

Pharmaceutical Sciences, Kyoto University, Sakyo-ku, Kyoto 606-8501, Japan.

Correspondence to:

Makiya Nishikawa, Ph.D., Department of Biopharmaceutics and Drug Metabolism, Graduate School of Pharmaceutical Sciences, Kyoto University, Sakyo-ku, Kyoto 606-8501, Japan

Phone: +81-75-753-4580

Fax: $+81-75-753-4614$

E-mail: makiya@pharm.kyoto-u.ac.jp 


\section{Contents}

1. Introduction

2. General requirements of DNA molecules for their pharmaceutical and biomedical application

\subsection{Stability}

2.2. Permeability

\subsection{Delivery issues}

3. DNA-based pharmaceuticals

4. DNA-mediated stimulation of innate immunity

4.1. Immunostimulatory activity of extracellular/cytosolic DNA

4.2. $\quad \mathrm{CpG}$ DNA as a signal of infection

4.3. Therapeutic applications of CpG DNA

5. DNA assemblies with designed architecture

5.1. General characteristics of DNA assemblies

5.2. Increased immunostimulatory activity of DNA by Y-shape formation

6. Conclusions and future perspectives

7. Acknowledgements

References 


\section{Abstract}

DNA is one of the most important components for all living organisms and many species, including humans, use DNA to store and transmit genetic information to new generations. Recent advances in the handling of DNA have made it possible to use DNA as a building block of nano-sized materials with precisely designed architectures. Although various approaches have been proposed to obtain DNA assemblies with designed architecture in the nano- to micrometer range, there is little information about their interaction with biological components, including target molecules. Understanding the interaction between DNA assemblies and the body is highly important for successful pharmaceutical and biomedical applications. Here, we first review the basic aspects of externally administered DNA molecules, including the stability, permeability and delivery issues. Then, we discuss the unique responses observed in the interaction of structured DNA assemblies and cells expressing Toll-like receptor-9, the receptor responsible for the recognition of unmethylated CpG dinucleotides that are abundant in the DNA of invading pathogens, such as bacteria and viruses.

Key words: DNA, nano-assembly, drug delivery, innate immunity, Toll-like receptor, CpG motif 


\section{Introduction}

DNA is one of the most important components of all living organisms. Genomic DNA is the archive of genetic information, which is the most important information for many species including humans, even though the sequence has always been continuously changing. This instability in terms of over millions of years has been changing the organisms, and some of those changes have allowed them to adapt to new environments and some others have resulted in their disappearance. For example, humans, other primates and guinea pigs have lost the ability to produce ascorbic acid, or vitamin C [1], even though they require the vitamin for healthy living. Genetic mutations sometimes cause diseases, even when only one base is deleted, or replaced by a different base if the change is critical to the expression of a functional protein at a normal level [2-5]. Most of mutations in genomic DNA are corrected by enzymatic systems to keep the information unchanged [6,7]. The double stranded structure of DNA makes this correction process precise, because the strand without mutations is used as a template for the correction.

From the structural point of view, there are many advantages in using DNA as a building block of nano-sized materials with precisely designed architecture [8-13]. In particular, the specificity of the hydrogen interactions between adenine-thymine and guanine-cytosine allows us to design the whole structure of DNA-based materials. In addition, two strands of double-stranded DNA can be covalently bound to each other using DNA ligase when the 5 '-end of one strand is complimentary to the 3'-end of another strand. Oligomers or polymers of DNA can be chemically synthesized by automated machines in a large quantities, so that DNA with a proper length and sequence can be obtained with high purity in amounts required for clinical application. Under conditions where there are no enzymes degrading DNA, DNA is very stable compared with proteins, another component candidate for nano-sized materials with designed architecture. Restriction enzymes, ligases and other 
enzymes are available to design and modify the properties of DNA-based materials.

Recent advances in the development of DNA assemblies have greatly increased the possibility of using DNA as a building block of nano-sized systems for pharmaceutical and biomedical applications. Various methods have been proposed and unique structures, most of which could not be imagined a few years ago, have been successfully developed [14-22]. In general, such systems use the property of DNA to hybridize its complimentary sequence. Any structure can be prepared if one can imagine it, in a nano- to micro-scale. Figure 1 shows some examples of DNA assemblies, the generation of which has been confirmed in these previous studies. These uniquely structured DNA assemblies rarely exist in nature, so that it is not clear how they are recognized by living organisms. On the other hand, they are composed of natural DNA, so that they could be handled in the same fashion as those of natural origin. Thus, it is very important to understand how DNA assemblies are recognized by the body in order to develop DNA-based nano-sized systems for pharmaceutical and biomedical use. In this review, we summarize the basic characteristics of DNA molecules, such as their stability, membrane permeability and tissue distribution properties, and discuss the use of DNA-based nano-sized systems for pharmaceutical and biomedical applications.

\section{General requirements of DNA molecules for their pharmaceutical and biomedical application}

To exhibit biological functions, the externally administered DNA should reach the site of action in a biologically active form, as required for other pharmaceutical compounds.

Generally speaking, there are two major hurdles in such applications of DNA molecules: one is biological instability and the other is poor ability to pass through biological membranes. Even though DNA is chemically stable compared with proteins, it is easily degraded within the body. Biological fluids, such as serum and extracellular fluid, and the cytosolic 
compartment contain DNases, DNA degrading enzymes [23]. Therefore, once recognized by these enzymes, DNA administered as a pharmaceutical agent will be degraded and no therapeutic benefits will be obtained.

DNA interacts with its target molecule once it reaches its site of action. If a DNA molecule is designed to interact with complementary DNA or RNA, the length of the DNA should be 15 nucleotides or longer to guarantee the specificity of binding to the target molecule [24]. This size limitation is determined by the size of the human genome. In addition, this length is also required to give the DNA a melting temperature high enough to form a stable duplex within cells under physiological conditions. However, these requirements are dependent on the type of nucleic acids.

An exception of DNA-based drugs is CpG DNA, an immunostimulatory compound, which exhibits its biological activity through the interaction with Toll-like receptor 9 (TLR9) [25]. TLR9 is localized in the endoplasmic reticulum and the endosomal/lysosomal compartments. Therefore, endocytic uptake, a major route for cellular uptake of macromolecules including DNA molecules, can sort CpG DNA to the subcellular compartments where TLR9 is localized. In this case, the membrane permeability does not prevent DNA from exhibiting its biological activity, and DNA as long as several thousand base pairs can induce a large amount of proinflammatory cytokines when its degradation is inhibited [26].

\subsection{Stability}

The problem of the biological instability of short strand of DNA, or oligodeoxynucleotide (ODN), has often been solved by chemical modification. Various forms of chemically modified ODN have been developed, includig phosphorothioate ODN, 2'-O-methyl ODN, morpholino ODN, methylphosphonate, phosphoramidate ODN and locked nucleic acid 
(Figure 2) [27-30]. Peptide nucleic acids (PNA), which are not DNA or RNA but can hybridize with a complementary DNA/RNA, have also been developed [31]. The binding affinity of PNA to complementary nucleic acids is much greater than DNA or RNA of the same sequence because of the absence of the negative charge in the PNA strand. Covalent linkage of other molecules, such as cholesterol, has been found to be another approach to increasing the stability of ODN $[32,33]$. These chemically modified ODNs are more stable than the natural phosphodiester ODN, because the recognition and cleavage by nucleases is at least partly impaired by such modifications.

Attention should be paid to these modifications, because some of them, if not all, can alter the specificity of ODN to interact with target molecules. In addition, the physiochemical characteristics of ODN will be greatly changed by these modifications which, in turn, affect their pharmacokinetic profile after in vivo administration. For instance, phosphorothioate ODN is extensively bound to proteins compared with phosphodiester ODN [34]. This change in the interaction with biological components can be advantageous for an increase in the biological half-life of ODN but, at the same time, it could be a cause of tissue damage when chemically modified ODN is extensively bound to the cell surface. The stable nature of modified ODN could increase the damage compared with that induced by phosphodiester ODN.

\subsection{Permeability}

Another problem, that of 'poor permeability', is difficult to solve, because it is closely related to the physicochemical nature of DNA/ODN. The monomer of DNA is a nucleotide, which is composed of 2'-deoxyribose, one of the nitrogenous bases, i.e., adenine, thymine, guanine or cytosine, and phosphoric acid. The average molecular mass of nucleotides in DNA is about 310. Considering that one of the smallest DNA molecules used as a pharmaceutical agent is 
single stranded and 15 bases in length, such small DNA molecules have a molecular weight of almost 5,000. Because of this size, DNA cannot easily pass through biological membranes. Furthermore, the large size of the DNA greatly limits the diffusion in the extracellular space and extravasation in tissues with a continuous endothelium [35-37]. In addition, the phosphoric acid gives the DNA a high negative charge. Since the cell surface is negatively charged because of the presence of negatively charged glycoproteins and glycolipids, the resulting electrical repulsion reduces the interaction of DNA with cells.

\subsection{Delivery issues}

In most cases, DNA should be delivered to the cytosol or the nucleus of cells of interest, where target molecules, such as DNA, RNA or proteins, exist. However, the large size and negative charge greatly restricts the entry of DNA into such subcellular compartments. Therefore, delivery systems should be considered in pharmaceutical applications to increase the intracellular delivery of such DNA molecules [38-42]. A simple and reliable delivery method is direct tissue injection of DNA [43-46]. This administration method is not limited to short DNA molecules, such as antisense ODN, but can be applied to huge plasmid DNA with a few thousand base pairs or more. The mechanism of the intracellular delivery of this method has not yet been fully elucidated, but damage to the membrane caused by the insertion of the needle and increased pressure due to the injection of solution into the extracellular spaces are believed to be involved in the intracellular delivery of DNA [47]. This mode of delivery is efficient, but a major drawback is the limited distribution of cells taking up DNA. A study on gene delivery reported that only cells located 5-10 $\mathrm{mm}$ from the injection site expressed the transgene after intramuscular injection of naked plasmid DNA $[\mathbf{4 8 , 4 9 ]}$. However, this method can be effective when the number of target cells is small and they are located within a limited area. This is the case for age-related macular degeneration, in which some nucleic acid drugs, 
such as antisense ODN, are directly injected into the vitrea [50-52]. Iontophoresis or electroporation can be used to increase the delivery of DNA and other charged molecules, which can be topically applied or injected into tissues [53-55].

For increased stability and effective delivery to the target site, DNA has been incorporated into particulate carriers, such as liposomes and micro-/nanospheres [56,57]. Incorporation of DNA into these particulates avoids the interaction of DNA with degrading enzymes, so that the stability of DNA is generally increased. Complex formation of DNA with cationic compounds, including cationic lipids, liposomes, and polymers, is another approach to increase the stability and delivery to the target site. Addition of these compounds to DNA generally results in the formation of complexes through an electrostatic interaction, and the surface of such complexes is positively charged. Then, these positively charged complexes can bind to the surface of cells, and eventually be internalized. Even though DNA is internalized, release from intracellular vesicles, such as endosomes and lysosomes, is required to reach the target DNA, RNA or proteins. Gene transfer studies have shown that the cytosolic delivery of DNA can be greatly increased by the use of molecules that disrupt or destroy the biological membranes [58-63].

\section{DNA-based pharmaceuticals}

Because of its fundamental roles in biological activities, DNA has been considered for use as a pharmaceutical agent to treat a variety of diseases. An important application of DNA to treating human diseases is in the field of gene therapy, where an inherent or acquired disease is treated by correcting the function of the mutated genes or by supplementing therapeutic genes $[\mathbf{6 4 , 6 5}$. Plasmid DNA, double stranded DNA amplified by polymerase chain reaction, DNA complexed with lipids, liposomes or polymers, and a variety of viruses, including adenovirus, adeno-associated virus, retrovirus and lentivirus, have been used to deliver the 
gene of interest to target cells, and many clinical trials have been conducted worldwide. As described above, DNA can carry the information for proteins, so that a successful delivery of DNA results in the expression of therapeutic proteins in cells reached by the DNA. In addition, RNA transcribed from DNA is another class of pharmaceutical agents, because RNA, especially those with a unique structure, i.e., about 21-23 nucleotide sense and antisense strands with 2 nucleotide overhangs at both 3' ends, so-called small interfering RNA (siRNA), are one of the most potent compounds to inhibit gene expression in a sequence specific manner [66]. Plasmid DNA can be used to deliver siRNA or short hairpin RNA, which is digested by dicer, a member of the RNase III family of enzymes, to siRNA [67].

In addition to the function as a provider of information about RNA or protein, DNA, especially short ones, exhibit a variety of biological functions in the form of DNA. For example, single stranded DNA can bind specifically to another DNA or RNA strand of a complementary sequence, and interferes with the function of the DNA/RNA. Organisms use the interaction of DNA with proteins in many biological processes, such as the regulation of gene expression, which is controlled by the binding of transcription factors (proteins) to their binding sites in the genome DNA. Such interactions can be modulated by DNA with suitable characteristics administered externally [27].

Various types of DNA and related molecules, such as chemically modified DNA, RNA and their hybrids, have been developed as candidates for pharmaceutical agents. The categories of nucleic acid drugs include: antisense DNA, ribozyme, decoy ODN, aptamer, CpG DNA and small interfering RNA (siRNA) [51,68]. These compounds exhibit their pharmacological activity by interacting with their target molecules. Antisense DNA is designed to bind to complementary RNA, so that the action of the protein translated from the RNA can be blocked. Ribozyme is an RNA enzyme that catalyzes specific cleavage of RNA molecules, and several modifications of the structure, such as DNA-RNA chimera, have been 
considered to increase the stability. siRNA is another, and the most recent, compound that can degrade target mRNA through the interaction with RNA inducible silencing complex.

Decoy ODN, a short double stranded DNA, is a "decoy" for transcription factors, such as nuclear factor- $\kappa \mathrm{B}$, and blocks the signaling through the transcription factor of interest [69]. In general, transcription factor binding motifs are $<10$ base pairs, so that double stranded DNA with about 20 base pairs are used as decoy DNA. When DNA binds to proteins other than transcription factors and modulates their functions, it is called an aptamer. DNA, RNA, chemically modified nucleic acids or their hybrids ranging from 20 to hundreds of bases in length have been examined for application as aptamers [70].

\section{DNA-mediated stimulation of innate immunity}

\subsection{Immunostimulatory activity of extracellular/cytosolic DNA}

DNA, which is stored in the nucleus and mitochondria in live cells, is released outside cells when cells are dying or dead. These DNA contain phosphodiester bonds, so that DNA degrading enzymes degrade the released DNA into small pieces. In addition to the enzymatic degradation, some cells, such as macrophages and liver sinusoidal endothelial cells, have an ability to take up extracellular DNA through mechanisms recognizing polyanions, and break it down by DNA degrading enzymes in the lysosomes [71-73]. Thus, DNA outside cells is quickly cleared or degraded by various endogenous mechanisms, and its concentration is kept very low [74-78]. When the homeostasis is impaired and the concentration of DNA in the cytosol or extracellular space is increased, DNA can be recognized as a danger signal $[\mathbf{7 9 , 8 0 ]}$. The amount of extracellular DNA increases in various pathophysiological conditions, including cancer, rheumatoid arthritis and other autoimmune diseases [81-84]. Recently, the binding of an antimicrobial peptide LL37 to self-DNA has been shown to convert the inert DNA into a potent trigger of interferon production [85]. These pieces of evidence clearly 
indicate that DNA is a bioactive compound once its instability in biological fluids is modified or prevented.

\section{2. $C p G D N A$ as a signal of infection}

It is potentially very dangerous if an individual is invaded by foreign pathogens, such as bacteria and viruses. To sense such invasions, the innate immune system of mammals uses Toll-like receptors (TLRs), a family of highly conserved pattern-recognizing receptors for self-defense [86]. TLRs recognize the unique structures of invaders, which include lipopolysaccharide, a component of the outer membrane of Gram-negative bacteria, peptidoglycan, a component of bacterial cell wall, and double stranded RNA, a component of RNA viruses. Each type of TLR has been evolved to detect one or more of these structures unique to, or abundant in, microbes. Although both mammals and microbes use DNA to transmit genetic information, there are some differences in the characteristics of the DNA. One very important difference between mammalian DNA and bacterial/viral DNA is that the C5 position of cytosine in CG dinucleotides in mammalian DNA is highly methylated [87]. In addition, the frequency of CG dinucleotides in mammalian DNA is much lower than the expected frequency of 1 out of 16 . These characteristics provide mammalian DNA with very few unmethylated $\mathrm{CG}$ dinucleotides (CpG motifs). This is not the case for bacterial and viral DNA, both of which contain unmethylated CG dinucleotides at a frequency close to the expected value. Therefore, the difference in the frequency of CpG motifs in DNA is used to sense the invasion of foreign microbes, and TLR9 is the receptor for the CpG motif. This sensing activates the innate immune system and proinflammatory cytokines are released from the TLR9-positive cells, such as dendritic cells.

\subsection{Therapeutic applications of $C p G D N A$}


Because of its ability to boost the innate immune response to cancer cells or virally infected cells, CpG DNA in various forms has been developed and used in preclinical and clinical trials [88]. The forms of CpG DNA developed thus far include short single stranded phosphorothioate DNA of several tens of bases, CpG-replete plasmid DNA, and their complex with cationic compounds. CpG DNA stimulates the production of Th1-type cytokines, including interleukin (IL)-12 and interferon (IFN)- $\gamma$, both of which have been shown to exhibit antitumor activity against a variety of tumors $[\mathbf{8 9 , 9 0 ] . ~ I n ~ a d d i t i o n , ~ i t ~ c a n ~ b e ~}$ considered to be effective in correcting the Th1/Th2 imbalance observed in a variety of allergic diseases.

\section{DNA assemblies with designed architecture}

\subsection{General characteristics of DNA assemblies}

DNA molecules of a small size are generally designed in a single- or double stranded form with a proper length, depending on the requirements for each category of nucleic acid drugs. These DNA drugs can be incorporated as a part of large DNA-based systems, or can be delivered using such systems, although such trials are in their infancy.

Recent major advances in developing nano-sized assemblies of DNA molecules have opened up new frontiers for the use of DNA as a building block of nano-sized materials with precisely designed architectures. Various methods have been reported and unique structures, such as DNA dendrimer [14], DNA barcode [91], DNA polyhedron [18] and DNA hydrogel [15], have appeared for the first time in the last decade (Figure 1). These 3-dimentional structures of DNA are constructed using the property of DNA to form duplexes with complementary strands. Some of these nano-sized DNA assemblies have been used in biomedical applications.

It is not yet well understood how DNA assemblies are recognized by the body, because 
such a structure cannot be found in nature. Even though the components are natural DNA, the overall structure of DNA assemblies may be handled in a different manner from that of simple single stranded- or double stranded DNA in linear or circular form. On the other hand, most DNA assemblies developed thus far are constructed using single stranded DNA with phosphodiester linkages of varying lengths. In addition, most of the assemblies consist of double stranded DNA. Therefore, the component parts of the DNA assemblies are exactly the same as natural DNA molecules, such as genome, bacterial and plasmid DNA, so that the body may not distinguish between them. In the following section, we briefly summarize our recent findings, which have clearly shown that Y-shaped DNA, a very simple type of DNA assembly, is recognized by TLR9-positive cells in a different manner from the natural form of straight (I-shaped) single- or double stranded DNA.

\subsection{Increased immunostimulatory activity of DNA by Y-shape formation}

One of the basic structures of DNA units for constructing DNA assemblies is a branched double stranded DNA, such as T-, X-, and Y-shaped DNA. These branched double stranded DNA molecules can be formed using three (for T- and Y-DNA) or four (X-DNA) ODNs with the halves of each ODN being partially complementary to half of the other two ODNs (Figure 3a). The Y-DNA has three double stranded DNA sequences, all of which are connected in the center of the structure. Therefore, the structural properties of Y-DNA are similar to those of double stranded DNA, except for the presence of a 3-way junction in the middle of the structure. Our previous study using several preparations of Y-DNA showed that (i) Y-DNA induced greater amounts of proinflammatory cytokines from RAW264.7 macrophage-like cells than double stranded DNA; and (2) greater amounts of Y-DNA were taken up by macrophage-like cells compared with double stranded DNA [92]. Figure 3b summarizes the tumor necrosis factor (TNF)- $\alpha$ concentration in the culture media of RAW264.7 cells that 
were mixed with several types of DNA molecules. As clearly demonstrated in this figure, the Y-shape formation was effective in increasing the immunostimulatory activity of DNA irrespective of the presence of CpG motifs in the DNA molecules. In addition, we found that the Y-DNA was not as stable as double stranded DNA. Preliminary studies using dendrimer-like DNA, which was constructed using several Y-DNA preparations as reported previously [14], showed that highly structured DNA assemblies are more potent immunostimulatory compounds than double stranded DNA [93]. Increased uptake of these DNA assemblies could be explained by experimental data showing that a longer DNA is more efficiently taken up by cells than a shorter one [94]. Further studies are required to determine the exact mechanism of the increased immunostimulatory activity of branched DNA preparations.

\section{Conclusions and future perspectives}

Technological advances have allowed us to modify DNA to become a bioinert or immunostimulatory compound with varying length and varying stability. The recent explosive expansion of knowledge about how to design and develop DNA assemblies will further increase the possibilities for the pharmaceutical and biomedical application of DNA molecules. Nano-sized compounds, such as liposomes, nanoparticles, macromolecular micelles and viruses, are useful for delivering pharmaceutical agents to specified sites, including solid tumors, and DNA-based nano-sized systems can also be used as a targeting vehicle for such sites. In addition, DNA can be a carrier for anthracyclines as demonstrated in the pioneer work of Trouet et al [95]. Therefore, DNA-based nano-sized systems consisting of DNA assemblies are a novel class of delivery systems for a wide variety of bioactive agents.

\section{Acknowledgements}


This work was supported in part by a Grant-in-Aid for Scientific Research from the Ministry of Education, Culture, Sports, Science and Technology, Japan, and by a grant from the Ministry of Health, Labour and Welfare, Japan. 


\section{References}

[1] R.N. Roy, B.C. Guha, Species difference in regard to the biosynthesis of ascorbic acid, Nature 182 (1958) 319-320.

[2] R.G. Roberts, M. Bobrow, D.R. Bentley, Point mutations in the dystrophin gene, Proc. Natl. Acad. Sci. USA 89 (1992) 2331-2325.

[3] G.R. Sutherland, R.I. Richards, Simple tandem DNA repeats and human genetic disease, Proc. Natl. Acad. Sci. USA 92 (1995) 3636-4361.

[4] D.J. Weatherall, Phenotype-genotype relationships in monogenic disease: lessons from the thalassaemias, Nat. Rev. Genet. 2 (2001) 245-225.

[5] P.A. Jones, S.B. Baylin, The epigenomics of cancer, Cell 128 (2007) 683-692.

[6] P. Modrich, R. Lahue, Mismatch repair in replication fidelity, genetic recombination, and cancer biology, Annu. Rev. Biochem. 65 (1996) 101-133.

[7] T.A. Kunkel, D.A. Erie, DNA mismatch repair, Annu. Rev. Biochem. 74 (2005) 681-710.

[8] N.C. Seeman, DNA engineering and its application to nanotechnology, Trends Biotechnol. 17 (1999) 437-443.

[9] N.C. Seeman, At the crossroads of chemistry, biology, and materials: structural DNA nanotechnology, Chem. Biol. 10 (2003) 1151-1159.

[10] N.C. Seeman, DNA in a material world, Nature 421 (2003) 427-431.

[11] U. Feldkamp, C.M. Niemeyer, Rational design of DNA nanoarchitectures, Angew. Chem. Int. Ed. Engl. 45 (2006) 1856-1876.

[12] A. Condon, Designed DNA molecules: principles and applications of molecular nanotechnology, Nat. Rev. Genet. 7 (2006) 565-575.

[13] F.C. Simmel, Three-dimensional nanoconstruction with DNA, Angew. Chem. Int. Ed. Engl. 47 (2008) 5884-5887. 
[14] Y. Li, Y.D. Tseng, S.Y. Kwon, L. D'Espaux, J.S. Bunch, P.L. McEuen, D. Luo, Controlled assembly of dendrimer-like DNA, Nat. Mater. 3 (2004) 38-42.

[15] S.H. Um, J.B. Lee, N. Park, S.Y. Kwon, C.C. Umbach, D. Luo, Enzyme-catalysed assembly of DNA hydrogel, Nat. Mater. 5 (2006) 797-801.

[16] P.W. Rothemund, Folding DNA to create nanoscale shapes and patterns, Nature 440 (2006) 297-302.

[17] R.P. Goodman, M. Heilemann, S. Doose, C.M. Erben, A.N. Kapanidis, A.J. Turberfield, Reconfigurable, braced, three-dimensional DNA nanostructures, Nat. Nanotechnol. 3 (2008) 93-96.

[18] Y. He, T. Ye, M. Su, C. Zhang, A.E. Ribbe, W. Jiang, C. Mao, Hierarchical self-assembly of DNA into symmetric supramolecular polyhedral, Nature 452 (2008) 198-201.

[19] C. Zhang, M. Su, Y. He, X. Zhao, P.A. Fang, A.E. Ribbe, W. Jiang, C. Mao, Conformational flexibility facilitates self-assembly of complex DNA nanostructures, Proc. Natl. Acad. Sci. USA 105 (2008) 10665-10669.

[20] W. Liu, X. Wang, T. Wang, R. Sha, N.C. Seeman, PX DNA triangle oligomerized using a novel three-domain motif, Nano Lett. 8 (2008) 317-322.

[21] K. Fujibayashi, R. Hariadi, S.H. Park, E. Winfree, S. Murata, Toward reliable algorithmic self-assembly of DNA tiles: a fixed-width cellular automaton pattern, Nano Lett. 8 (2008) 1791-1797.

[22] S.H. Park, G. Finkelstein, T.H. LaBean, Stepwise self-assembly of DNA tile lattices using dsDNA bridges, J. Am. Chem. Soc. 130 (2008) 40-41.

[23] D. Nadano, t. Yasuda, K. Kishi, Measurement of deoxyribonuclease I activity in human tissues and body fluids by a single radial enzyme-diffusion method, Clin. Chem. 39 (1993) 448-452. 
[24] A. Nicot, D.W. Pfaff, Antisense oligodeoxynucleotides as specific tools for studying neuroendocrine and behavioral functions: some prospects and problems, J. Neurosci. Methods 71 (1997) 45-53.

[25] A.M. Krieg, CpG motifs in bacterial DNA and their immune effects, Annu. Rev. Immunol. 20 (2002) 709-760.

[26] K. Yasuda, Y. Ogawa, I. Yamane, M. Nishikawa, Y. Takakura, Macrophage activation by a DNA/cationic liposome complex requires endosomal acidification and TLR9-dependent and -independent pathways, J. Leukoc. Biol. 77 (2005) 71-79.

[27] R.W. Wagner, Gene inhibition using antisense oligodeoxynucleotides, Nature 372 (1994) 333-335.

[28] S.T. Crooke, Progress in antisense technology, Annu. Rev. Med. 55 (2004) 61-95.

[29] S.T. Crooke, Antisense strategies, Curr. Mol. Med. 4 (2004) 465-487.

[30] A. Grünweller, E. Wyszko, B. Bieber, R. Jahnel, V.A. Erdmann, J. Kurreck, Comparison of different antisense strategies in mammalian cells using locked nucleic acids, 2'-O-methyl RNA, phosphorothioates and small interfering RNA, Nucleic Acids Res. 31 (2003) 3185-3193.

[31] P. Wittung, P.E. Nielsen, O. Buchardt, M. Egholm, B. Nordén, DNA-like double helix formed by peptide nucleic acid, Nature 368 (1994) 561-563.

[32] S.K. Alahari, N.M. Dean, M.H. Fisher, R. Delong, M. Manoharan, K.L. Tivel, R.L. Juliano, Inhibition of expression of the multidrug resistance-associated P-glycoprotein of by phosphorothioate and 5' cholesterol-conjugated phosphorothioate antisense oligonucleotides, Mol. Pharmacol. 50 (1996) 808-819.

[33] M. Manoharan, Oligonucleotide conjugates as potential antisense drugs with improved uptake, biodistribution, targeted delivery, and mechanism of action, Antisense Nucleic Acid Drug Dev. 12 (2002) 103-128. 
[34] D.A. Brown, S.H. Kang, S.M. Gryaznov, L. DeDionisio, O. Heidenreich, S. Sullivan, X. Xu, M.I. Nerenberg, Effect of phosphorothioate modification of oligodeoxynucleotides on specific protein binding, J. Biol. Chem. 269 (1994) 26801-26805.

[35] E. Nara, M. Masegi, T. Hatono, M. Hashida, Pharmacokinetic analysis of drug absorption from muscle based on a physiological diffusion model: effect of molecular size on absorption, Pharm. Res. 9 (1992) 161-168.

[36] M. Nishikawa, M. Hashida, Pharmacokinetics of anticancer drugs, plasmid DNA, and their delivery systems in tissue-isolated perfused tumors, Adv. Drug Deliv. Rev. 40 (1999) 19-37.

[37] O. Cleaver, D.A. Melton, Endothelial signaling during development, Nat. Med. 9 (2003) 661-668.

[38] O. Boussif, F. Lezoualc'h, M.A. Zanta, M.D. Mergny, D. Scherman, B. Demeneix, J.P. Behr, A versatile vector for gene and oligonucleotide transfer into cells in culture and in vivo: polyethyleneimine, Proc. Natl. Acad. Sci. USA 92 (1995) 7297-7301.

[39] Y. Takakura, M. Hashida, Macromolecular carrier systems for targeted drug delivery: pharmacokinetic considerations on biodistribution, Pharm. Res. 13 (1996) 820-831.

[40] R.I. Mahato, Y. Takakura, M. Hashida, Development of targeted delivery systems for nucleic acid drugs, J. Drug Target. 4 (1997) 337-357.

[41] Y. Kakizawa, K. Kataoka, Block copolymer micelles for delivery of gene and related compounds, Adv. Drug Deliv. Rev. 54 (2002) 203-222.

[42] T. Merdan, J. Kopecek, T. Kissel, Prospects for cationic polymers in gene and oligonucleotide therapy against cancer, Adv. Drug Deliv. Rev. 54 (2002) 715-758.

[43] J.A. Wolff, R.W. Malone, P. Williams, W. Chong, G. Acsadi, A. Jani, P.L. Felgner, Direct gene transfer into mouse muscle in vivo, Science 247 (1990) 1465-1468.

[44] M. Nishikawa, L. Huang, Nonviral vectors in the new millennium: delivery barriers in 
gene transfer, Hum. Gene Ther. 12 (2001) 861-870.

[45] M. Nishikawa, M. Hashida, Nonviral approaches satisfying various requirements for effective in vivo gene therapy, Biol. Pharm. Bull. 25 (2002) 275-283.

[46] O. Thanaketpaisarn, M. Nishikawa, F. Yamashita, M. Hashida, Tissue-specific characteristics of in vivo electric gene transfer by tissue and intravenous injection of plasmid DNA, Pharm. Res. 22 (2005) 883-891.

[47] N. Kobayashi, M. Nishikawa, Y.Takakura, Gene therapy and gene delivery, In: B. Wang, T.J. Siahaan, R. Soltero (eds.), Drug Delivery: Principles and Applications, John Wiley \& Sons, Inc. (2005) 305-319.

[48] M.A. Hickman, R.W. Malone, K. Lehmann-Bruinsma, T.R. Sih, D. Knoell, F.C. Szoka, R. Walzem, D.M. Carlson, J.S. Powell, Gene expression following direct injection of DNA into liver, Hum. Gene Ther. 5 (1994) 1477-1483.

[49] A.J. O'Hara, J.M. Howell, R.H. Taplin, S. Fletcher, F. Lloyd, B. Kakulas, H. Lochmüller, G. Karpati, The spread of transgene expression at the site of gene construct injection, Muscle Nerve 24 (2001) 488-495.

[50] Vitravene study group, A randomized controlled clinical trial of intravitreous fomivirsen for treatment of newly diagnosed peripheral cytomegalovirus retinitis in patients with AIDS, Am. J. Ophthalmol. 133 (2002) 467-474.

[51] E. Fattal, A. Bochot, Ocular delivery of nucleic acids: antisense oligonucleotides, aptamers and siRNA, Adv. Drug Deliv. Rev. 58 (2006) 1203-1223.

[52] A. de Fougerolles, H.P. Vornlocher, J. Maraganore, J. Lieberman, Interfering with disease: a progress report on siRNA-based therapeutics, Nat. Rev. Drug Discov. 6 (2007) 443-453.

[53] V. Regnier, V. Préat, Localization of a FITC-labeled phosphorothioate oligodeoxynucleotide in the skin after topical delivery by iontophoresis and 
electroporation, Pharm. Res. 15 (1998) 1596-1602.

[54] H. Aihara, J. Miyazaki, Gene transfer into muscle by electroporation in vivo, Nat. Biotechnol. 16 (1998) 867-870.

[55] R.M. Brand, P.L. Iversen, Transdermal delivery of antisense compounds, Adv. Drug Deliv. Rev. 44 (2000) 51-57.

[56] C. Garcia-Chaumont, O. Seksek, J. Grzybowska, E. Borowski, J. Bolard, Delivery systems for antisense oligonucleotides, Pharmacol. Ther. 87 (2000) 255-277.

[57] G. Lambert, E. Fattal, P. Couvreur, Nanoparticulate systems for the delivery of antisense oligonucleotides, Adv. Drug Deliv. Rev. 47 (2001) 99-112.

[58] P. Pinnaduwage, L. Schmitt, L. Huang, Use of a quaternary ammonium detergent in liposome mediated DNA transfection of mouse L-cells, Biochim. Biophys. Acta 985 (1989) 33-37.

[59] E. Wagner, C. Plank, K. Zatloukal, M. Cotten, M.L. Birnstiel, Influenza virus hemagglutinin HA-2 N-terminal fusogenic peptides augment gene transfer by transferrin-polylysine-DNA complexes: toward a synthetic virus-like gene-transfer vehicle, Proc. Natl. Acad. Sci. USA 89 (1992) 7934-7938.

[60] J.G. Lewis, K.Y. Lin, A. Kothavale, W.M. Flanagan, M.D. Matteucci, R.B. DePrince, R.A. Mook Jr, R.W. Hendren, R.W. Wagner, A serum-resistant cytofectin for cellular delivery of antisense oligodeoxynucleotides and plasmid DNA, Proc. Natl. Acad. Sci. USA 93 (1996) 3176-3181.

[61] H. Mizuguchi, T. Nakagawa, M. Nakanishi, S. Imazu, S. Nakagawa, T. Mayumi, Efficient gene transfer into mammalian cells using fusogenic liposome, Biochem. Biophys. Res. Commun. 218 (1996) 402-407.

[62] E. Wagner, Application of membrane-active peptides for nonviral gene delivery, Adv. Drug Deliv. Rev. 38 (1999) 279-289. 
[63] Y. Kaneda, Applications of Hemagglutinating Virus of Japan in therapeutic delivery systems, Expert Opin. Drug Deliv. 5 (2008) 221-233.

[64] R.C. Mulligan, The basic science of gene therapy, Science 260 (1993) 926-932.

[65] I.M. Verma, N. Somia, Gene therapy -- promises, problems and prospects, Nature 389 (1997) 239-242.

[66] T. Tuschl, Expanding small RNA interference, Nat. Biotechnol. 20 (2002) 446-448.

[67] E. Bernstein, A.A. Caudy, S.M. Hammond, G.J. Hannon, Role for a bidentate ribonuclease in the initiation step of RNA interference, Nature 409 (2001) 363-366.

[68] A. Dove, Antisense and sensibility, Nat. Biotechnol. 20 (2002) 121-124.

[69] N. Tomita, T. Ogihara, R. Morishita, Transcription factors as molecular targets: molecular mechanisms of decoy ODN and their design, Curr. Drug Targets 4 (2003) 603-608.

[70] S.M. Nimjee, C.P. Rusconi, B.A. Sullenger, Aptamers: an emerging class of therapeutics, Annu. Rev. Med. 56 (2005) 555-583.

[71] T. Takagi, M. Hashiguchi, R.I. Mahato, H. Tokuda, Y. Takakura, M. Hashida, Involvement of specific mechanism in plasmid DNA uptake by mouse peritoneal macrophages, Biochem. Biophys. Res. Commun. 245 (1998) 729-733.

[73] T. Yoshinaga, K. Yasuda, Y. Ogawa, Y. Takakura, Efficient uptake and rapid degradation of plasmid DNA by murine dendritic cells via a specific mechanism, Biochem. Biophys Res. Commun. 299 (2002) 389-394.

[73] J. Hisazumi, N. Kobayashi, M. Nishikawa, Y. Takakura, Significant role of liver sinusoidal endothelial cells in hepatic uptake and degradation of naked plasmid DNA after intravenous injection, Pharm. Res. 21 (2004) 1223-1228.

[74] W. Emlen, M. Mannik, Kinetics and mechanisms for removal of circulating single-stranded DNA in mice, J. Exp. Med. 147 (1978) 684-699. 
[75] W. Emlen, M. Mannik, Effect of DNA size and strandedness on the in vivo clearance and organ localization of DNA, Clin. Exp. Immunol. 56 (1984) 185-192.

[76] V.J. Gauthier, L.N. Tyler, M. Mannik, Blood clearance kinetics and liver uptake of mononucleosomes in mice, J. Immunol. 156 (1996) 1151-1156.

[77] K. Kawabata, Y. Takakura, M. Hashida, The fate of plasmid DNA after intravenous injection in mice: involvement of scavenger receptors in its hepatic uptake, Pharm. Res. 12 (1995) 825-830.

[78] N. Kobayashi, T. Kuramoto, K. Yamaoka, M. Hashida, Y. Takakura, Hepatic uptake and gene expression mechanisms following intravenous administration of plasmid DNA by conventional and hydrodynamics-based procedures, J. Pharmacol. Exp. Ther. 297 (2001) 853-860.

[79] K.J. Ishii, K. Suzuki, C. Coban, F. Takeshita, Y. Itoh, H. Matoba, L.D. Kohn, D.M. Klinman, Genomic DNA released by dying cells induces the maturation of APCs, J. Immunol. 167 (2001) 2602-2607.

[80] M. Skoberne, A.S. Beignon, N. Bhardwaj, Danger signals: a time and space continuum, Trends Mol. Med. 10 (2004) 251-257.

[81] S. Jahr, H. Hentze, S. Englisch, D. Hardt, F.O. Fackelmayer, R.D. Hesch, R. Knippers, DNA fragments in the blood plasma of cancer patients: quantitations and evidence for their origin from apoptotic and necrotic cells, Cancer Res. 61 (2001) 1659-1665.

[82] R. Licht, M.C. van Bruggen, B. Oppers-Walgreen, T.P. Rijke, J.H. Berden, Plasma levels of nucleosomes and nucleosome-autoantibody complexes in murine lupus: effects of disease progression and lipopolyssacharide administration, Arthritis Rheum. 44 (2001) 1320-1330.

[83] B.G. Wang, H.Y. Huang, Y.C. Chen, R.E. Bristow, K. Kassauei, C.C. Cheng, R. Roden, L.J. Sokoll, D.W. Chan, I. Shih, Increased plasma DNA integrity in cancer patients, 
Cancer Res. 63 (2003) 3966-3968.

[84] N. Jiang, D.S. Pisetsky, The effect of inflammation on the generation of plasma DNA from dead and dying cells in the peritoneum, J. Leukoc. Biol. 77 (2005) 296-302.

[85] R. Lande, J. Gregorio, V. Facchinetti, B. Chatterjee, Y.H. Wang, B. Homey, W. Cao, Y.H. Wang, B. Su, F.O. Nestle, T. Zal, I. Mellman, J.M. Schröder, Y.J. Liu, M. Gilliet, Plasmacytoid dendritic cells sense self-DNA coupled with antimicrobial peptide, Nature 449 (2007) 564-569.

[86] K. Takeda, T. Kaisho, S. Akira, Toll-like receptors, Annu. Rev. Immunol. 21 (2003) $335-376$.

[87] A.M. Krieg, CpG motifs in bacterial DNA and their immune effects, Annu. Rev. Immunol. 20 (2002) 709-760.

[88] A.M. Krieg, Therapeutic potential of Toll-like receptor 9 activation, Nat. Rev. Drug Discov. 5 (2006) 471-484.

[89] M.J. Smyth, M. Taniguchi, S.E. Street, The anti-tumor activity of IL-12: mechanisms of innate immunity that are model and dose dependent, J. Immunol. 165 (2000) 2665-2670.

[90] S. Baron, S.K. Tyring, W.R. Fleischmann Jr, D.H. Coppenhaver, D.W. Niesel, G.R. Klimpel, G.J. Stanton, T.K. Hughes, The interferons. Mechanisms of action and clinical applications, JAMA 266 (1991) 1375-1383.

[91] S.H. Um, J.B. Lee, S.Y. Kwon, Y. Li, D. Luo, Dendrimer-like DNA-based fluorescence nanobarcodes, Nat. Protoc. 1 (2006) 995-1000.

[92] M. Nishikawa, M. Matono, S. Rattanakiat, N. Matsuoka, Y. Takakura, Enhanced immunostimulatory activity of oligodeoxynucleotides by Y-shape formation, Immunology 124 (2008) 247-255.

[93] S. Rattanakiat, M. Nishikawa, H. Funabashi, D. Luo, Y. Takakura, The assembly of a 
short linear natural cytosine-phosphate-guanine DNA into dendritic structures and its effect on immunostimulatory activity, Biomaterials in press.

[94] T.L. Roberts, J.A. Dunn, T.D. Terry, M.P. Jennings, D.A. Hume, M.J. Sweet, K.J. Stacey, Differences in macrophage activation by bacterial DNA and CpG-containing oligonucleotides, J. Immunol. 175 (2005) 3569-3576.

[95] A. Trouet, D. Deprez-de Campeneere, C. De Duve, Chemotherapy through lysosomes with a DNA-daunorubicin complex, Nat. New Biol. 239 (1972) 110-112. 


\section{FIGURE LEGENDS}

Fig. 1. Schematic presentation of a variety of DNA assemblies. In most cases, double strand formation between two DNA molecules is the driving force to form DNA assemblies. (a) Y-DNA, (b) X-DNA, (c) dendrimaer-like DNA (Y-DNA based), (d) DNA tetrahedron, and (e) DNA dodecahedron. Each line represents one (a-c) or more (d,e) DNA strands.

Fig. 2. Structures of natural (phosphodiester) DNA and several DNA derivatives. Most DNA derivatives are more resistant to degradation by DNases than phosphodiesters. (a) phosphodiester DNA, (b) phosphothioate DNA, (c) methylphosphonate DNA, (d) 2'-O-methyl RNA (X=O or S), (e) locked nucleic acid, (f) morpholino and (g) PNA.

Fig.3. Increased immunostimulatory activity of DNA by Y-shape formation. (a) The sequence and putative structure of the preparations of Y-DNA. (b) Concentrations of TNF- $\alpha$ in culture media of RAW264.7 cells mixed with each type of DNA. (Closed bars) TNF- $\alpha$, (open bars) IL-6. 
Figure 1

(a)

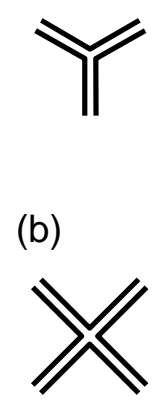

(c)

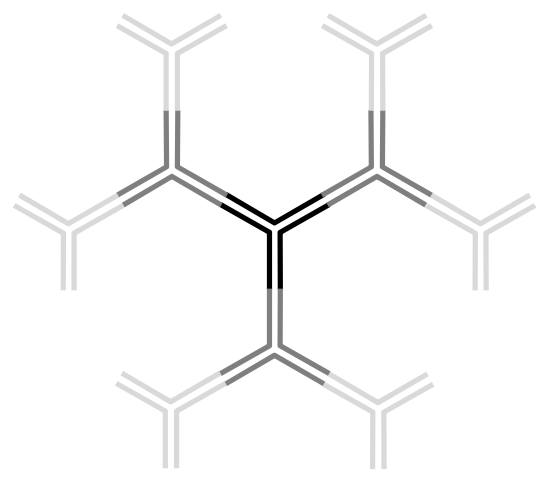

(d)

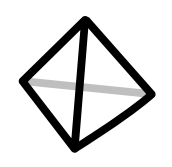

(f)

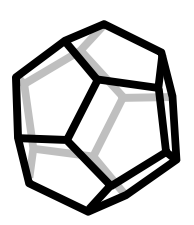


Figure 2

(a)

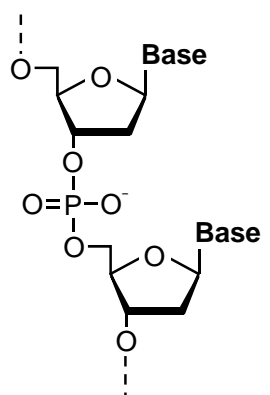

(e)

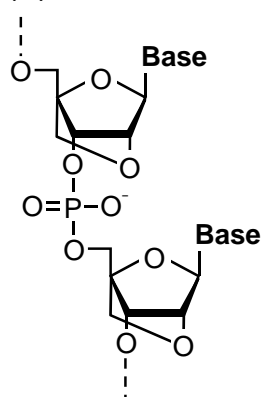

(b)

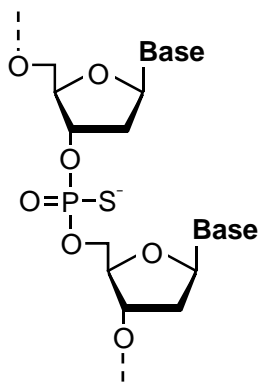

(f)

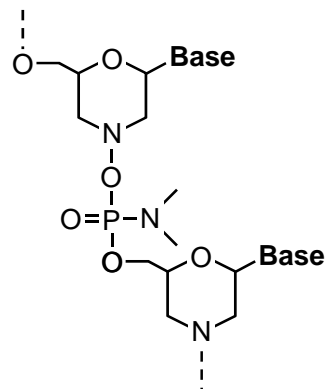

(c)

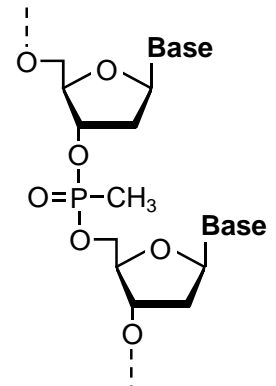

(g)

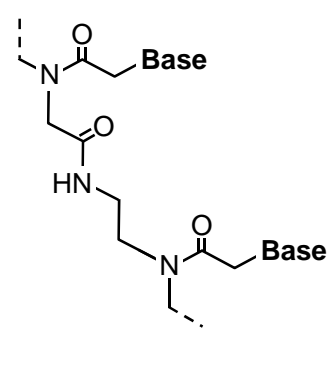


Figure 3

(a)
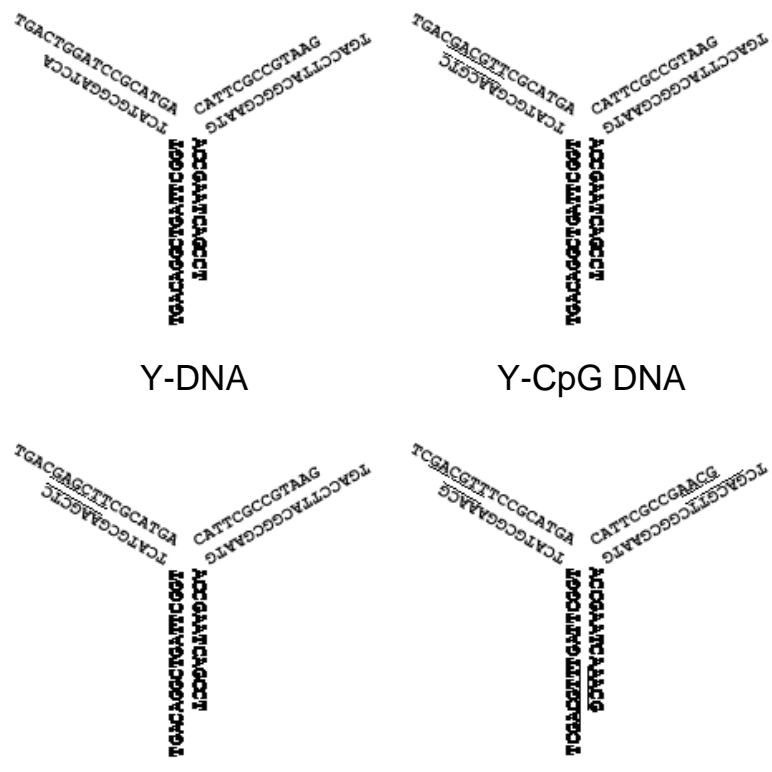

Y-GpC DNA

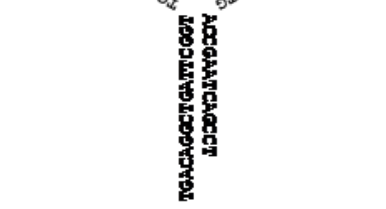

Y-CpG DNA

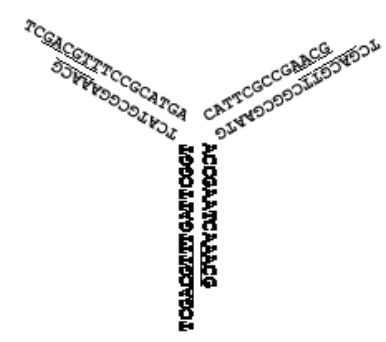

$\mathrm{Y}-(\mathrm{CpG})_{3} \mathrm{DNA}$

(b)

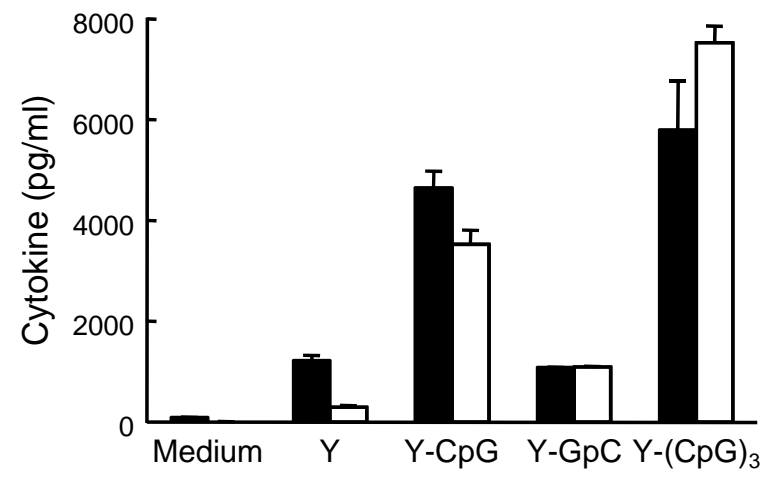

